\title{
Smart grid terminology development-crossing the boundaries of terminology standardization
}

\author{
Susanne Arndt ${ }^{*}$, Tatyana Sheveleva ${ }^{2}$ and Christoph Goeker ${ }^{3}$
}

\begin{abstract}
Background: Standardization is concerned with ongoing terminology standardization activities. Activities are rather complex in divergent topics and current themes of interest. The article is concerned with terminology standardization activities in Germany and international standardization activities for smart grids and smart-grid-related topics like smart metering systems, smart homes, and electromobility. Even though standardization topics are very clearly organized by standardization road maps, and responsibilities are distributed among working groups, there are still conceptual overlaps between activities of different groups that will result in inconsistencies and ambiguities in their respective glossaries. These glossaries, however, undergo only a limited process of synchronization during their development, especially on the level of single concepts and terms. The application of inconsistent and ambiguous terminology in standards may later on reduce their internal and external consistency, readability, and understandability. To create high-quality standards, conceptual consistency needs to be guaranteed. To do this, terminologies under development should be made more openly available to standardization working groups in the development phase (and not only after completion). Furthermore, additional synchronization tasks on the conceptual level are needed to generate consistent and clear conceptualizations of new technologies.
\end{abstract}

Methods: A number of glossaries have been analyzed for overlaps as described by this article.

Results: The article gives an overview of issues found in the respective glossaries, and the process can lead to proposals which may be put to vote among domain experts.

Conclusions: Overall, domain experts working on terminologies should be given more assistance as regards terminological and linguistic knowledge and methodology to assure linguistic and terminological next to technical quality of their terminologies. Future work will be dedicated to issue resolution and assistance for issue identification.

\section{Background}

Energy transition-challenges and aims

With the emerging trend to create an environmentally friendly future, the need for development and dissemination of innovative environmentally friendly technologies is growing. One of these technologies currently being under intensive development is a fully automated intelligent energy systems based on future smart grids [1]. The projected merging of smart grids with grid-related domains such as electric mobility, smart home, and smart

\footnotetext{
* Correspondence: arndt@iva.ing.tu-bs.de

${ }^{1}$ Institut für Verkehrssicherheit und Automatisierungstechnik, Technische Universität Braunschweig, Hermann-Blenk-Straße 42, 38108 Braunschweig, Germany

Full list of author information is available at the end of the article
}

metering will give rise to a huge "energy organism". Its development requires a multidisciplinary approach that unifies the knowledge of many different scientific areas like automation engineering, electrical engineering, information technology, automotive engineering, or even architecture.

Successful integration of such a complex technology requires standardization of knowledge. Co-participating players of those different domains need to develop national and international technical standards with the aim of harmonization of construction, production, and use of smart grids. Standardized knowledge, however, is among other factors based on linguistic clarity which can only be achieved when experts try to standardize the smart grid terminology within their groups. To provide

\section{曾}


an overview about the whole existing smart grid terminology, the technical standardization bodies continually collect these terminological units to use them as lexicological basis for standardization activities aiming at providing technical standards.

From the high amount of different players working on the development of smart grids, it can be assumed that a certain amount of similar terminology already exists. Moreover, because of the high innovation degree of smart grid technology, a high amount of new concepts has and will be introduced by scientific organizations and businesses to standards. Therefore, terminology work of standardization bodies is not a mere collection of terminological elements but the creation of new ones. This implies thorough investigation of the discourse of a domain, its description, and probably even the introduction of completely new concepts into the domain. It is therefore to be expected that terminological problems like synonymy or homonymy will occur, since new developments take place and a lack of coordination leads to different terms for objects and phenomena that are in direct competition for a while until the harmonization of a terminology is conducted [2].

Actual integration of such technologies into ordinary society requires social acceptance, which then again is based on understandability of such technology by society [3]. The development of such understanding results through communication and use of specified vocabulary [4].

A terminological analysis presented in this article takes up the issue of terminological ambiguity and conceptual overlaps in smart-grid-related glossaries from domains like smart home, electric mobility, and smart meter. In conclusion, a suggestion for the improvement of terminological work in standardization groups will be made.

\section{Basic concepts of terminology work}

Terminology standardization is defined by DIN 2342:201108 as the

"standardization of concepts and their terms as well as of concept systems by authorized committees with appropriate domain-specific, linguistic and methodical qualifications aiming at terminological definitions in standards"

(translated by the authors from the original quote: "Normung von Begriffen und ihren Benennungen sowie von Begriffssystemen durch autorisierte und dafür fachlich, sprachlich und methodisch qualifizierte Gremien mit dem Ziel, terminologische Festlegungen in Normen zu schaffen" (DIN 2342:2011-08))

Concepts are mental entities that are achieved by abstraction of real world phenomena and objects based on their similarity according to characteristics. For innovative technologies, this abstraction process is a research task, which should in the end lead to an adequate account of the observed phenomena and objects. Experts of the respective domain should agree on that account when they are not able to falsify it. Only after conceptual standardization, terminological standardization can be achieved. This includes the structuring of concepts within their conceptual context, the concept system.

Conceptual standardization therefore is a prerequisite for the standardization of terms for those concepts. There are at least five aims:

1. Thorough but purpose-driven understanding of relevant concepts

2. Adequate and unambiguous definition of concepts

3. Identification of existing terms for concepts

4. Standardized use of terms

5. Use of understandable, precise, economic terms

The relation of real world phenomena and objects, concepts, terms, and definitions is demonstrated in Fig. 1.

Concepts as mental units of knowledge serve as a means of representation for real world objects. Since they are relatively tied to individual cognitive entities, their standardization must be driven by communication. The use of means of representation is therefore inevitable: concepts are referred to by terms, terms indirectly refer to objects. To standardize and synchronize concepts, they need to be explained in their contexts, which includes the identification of and an agreement on relevant contexts. Such explanations need to make use of further terms to specify the relations between concepts. In terminology standardization, these relations are usually given by definitions and short descriptive texts. The whole process of defining concept-term-relations follows

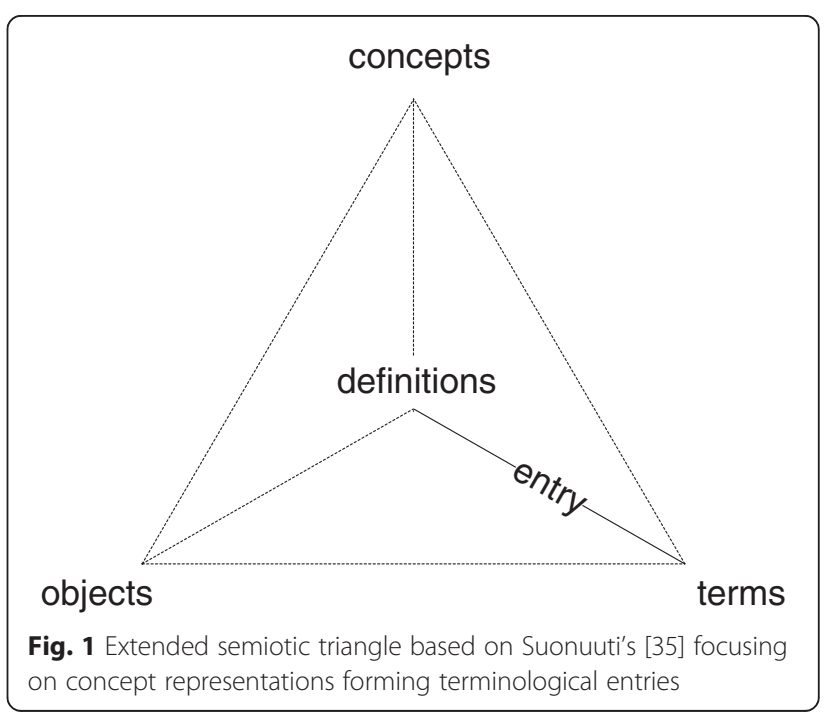


the principle of concept orientation: the concept is the focus point for the structuring of terminological data.

A major problem for terminologies is that terms and concepts are not bijectively mapped onto each other:

"Concepts and terms develop differently in individual languages and language communities, depending on professional, technical, scientific, social, economic, linguistic, cultural or other factors. Harmonization is, therefore, desirable because

- differences between concepts do not necessarily become apparent at the designation level,

- similarity at the designation level does not necessarily mean that the concepts behind the designations are identical,

- mistakes occur when a single concept is designated by two synonyms which by error are considered to designate two different concepts" [5]

Mistakes can also occur when two very different concepts are designated by the same term. To avoid these mistakes, one needs to understand terminological standardization as "an integral part of standardization" [5]. A useful terminology should therefore make clear, which relations exist between its terms and concepts. Once these relations are known, concept systems can be made conscious. The uncovering of such relations maps sets of terms to their concepts. This implies the identification of concepts and their relations to each other. This allows for consistent and explicit labelling of designative ambiguities. Such relations between terms and concepts are illustrated in Fig. 2.

When one term represents different concepts, the concept-term-relation is called homonymy (1). Consider, for example, the term virus that receives distinct interpretations in medicine or computer sciences. When one term represents several very similar concepts, the concept-term-relation is called polysemy (2), for example, in pull as an act of inhaling as compared to pull as a deep draught of a drink, where the consumed medium differs. When several terms represent one concept, the concept-term-relation is called synonymy (3). For example, car and automobile can be considered synonyms.

Without terminological standardization, languages for special purposes cannot be effective tools for their specific purposes since they are likely to be vague and cause misunderstandings during communication. Nevertheless, even though terminological standardization is accepted as a necessity, there are certain boundaries.

\section{The boundaries of terminology standardization}

The definition of terminology standardization must be considered an ideal. Standardization bodies often cannot apply common state-of-the-art terminological knowledge and tools, thus they are restricted in their linguistic and methodical means needed for terminology-related tasks. It is, however, especially for motivational reasons, desirable not to bother domain experts with the acquisition of domain-external skills. Instead, trained terminologists should accompany standardization committees so that linguistic and methodic services are experienced as an added value.

Experts often work term-oriented, that is, experts often see their task as collecting a list of terms and defining each of them-disregarding related domains, alternative terms, and deviant usage of the term. Resulting glossaries are thus only marginally concerned with concepts and concept structures but rather with single terms. Conceptual structuring is followed only unsystematically, only when equivalents or acronyms play a role or when domain experts are already aware of ambiguities. The processing of terminological data is therefore often conducted with two-dimensional spreadsheets without measures for concept identification (see "Smartgrid-related glossaries" section).

Further complications are caused when standardization is concerned with converging technologies. As the standardization roadmap of German Commission for Electrical, Electronic and Information Technologies (DKE) and German Association for Electrical,

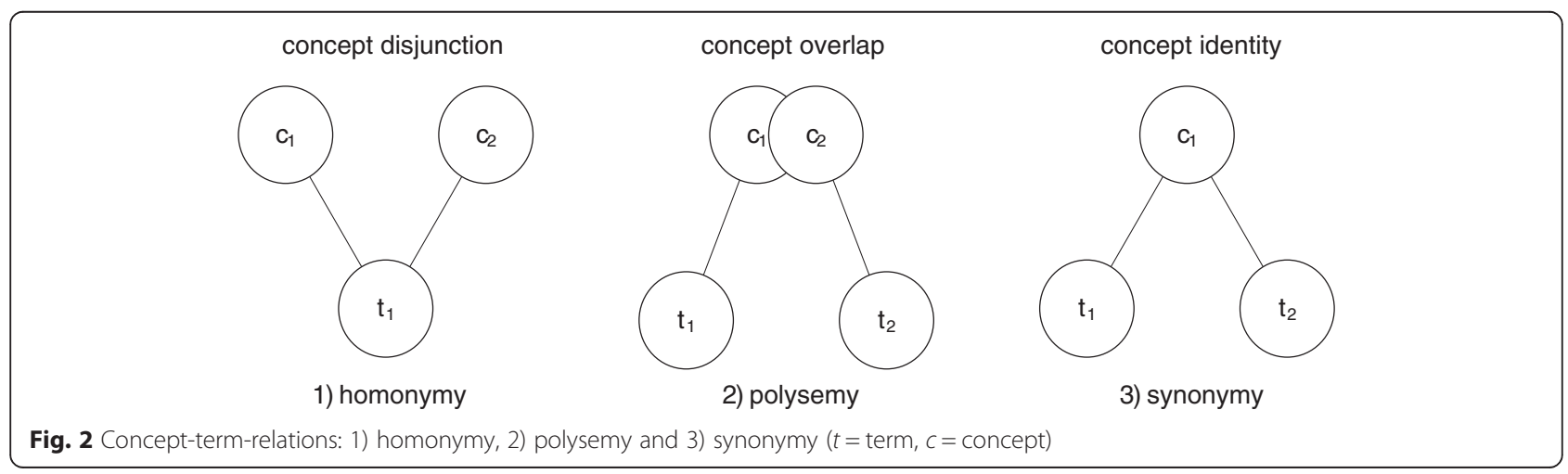


Electronic and Information Technologies (VDE) states, in such cases standardization is no longer "business as usual" [6]. Convergence affects standardization in different ways.

First, by making it difficult to determine which knowledge is the object of standardization. Converging technologies rely on innovative concepts and often research activities that try to explore the possibilities and feasibility of such concepts. Research activities, however, are initially characterized by diversity and exploration of different possibilities of bringing innovative concepts to practice. Especially for convergent technologies, results are not achieved by isolated projects so that the concept of $R \& D$ phase standardization might not go far enough to bring innovations to standards and preliminary results are introduced to standardization [6] (for the concept of R\&D phase standardization see also [7]).

Second, by involving a multitude of different disciplines that make opting for interdisciplinary or even transdisciplinary approaches necessary. This requires experts of different domains to work on the same topic in a joint endeavor and to overcome boundaries of domain-specific knowledge, language, or methodology [6].

Third, by being under pressure from economical or societal parties that have an interest in the fast development of converging technologies, as is the case with smart grid technologies that ultimately serve the goal to prevent climate change and energy bottlenecks by integration of highly decentralized renewable energy sources. Further complication is brought by political efforts of legal regulation [6].

Fourth, by being highly relevant on an international scale, there are standardization activities all around the globe, which result in highly diversified conceptualizations of the smart grid. Furthermore, standardization efforts are not only segmentalized internationally but also locally. Committees are mostly organized hierarchically according to domains, and subjects are divided among them, as is demonstrated in Fig. 3.

Contrarily, it is necessary to consider thematic interrelations that blur the boundaries of committees and to understand the committee boundaries as more fuzzy. This has been done in the standardization roadmaps. The committees highlighted in Fig. 3, for example, have been identified as being commonly responsible for the operational safety of the charging infrastructure of electrical installations [8].

Strict subject segmentalizations, however, already caused problems in classic standardization processes, especially on the conceptual level. Due to the strict hierarchical organization of standardization bodies, interrelations between subjects may be neglected or overlooked and thus result in parallel activities on the conceptual level. Different groups happen to work on the same topic at least partially, since topics are related to each other in micro-aspects. The same referent when viewed by different experts may lead to different, inconsistent mental representations (concepts) to

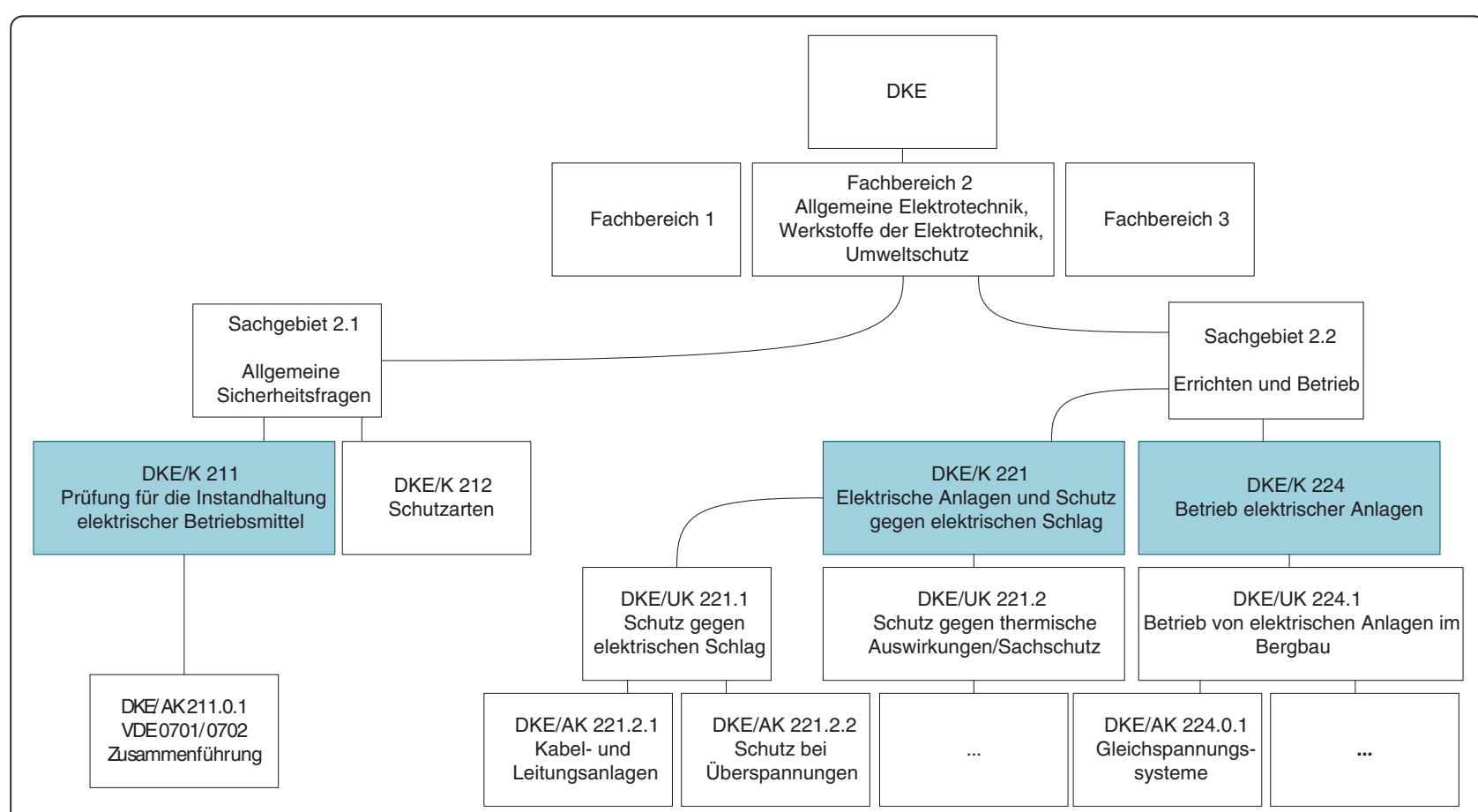

Fig. 3 Hierarchical organization of standardization committees exemplified for DKE (cf. www.iso.org, www.din.de, www.dke.de, www.cencenelec.eu) 
emerge, which are differently represented by language, either in definition or terms.

It is thus very common for standardization bodies on all levels (regional, super-regional, international) often to provide an inconsistent, ambiguous set of concept, terms, and definitions. This is especially true for subjects that are relevant in a wide range of domains (for example, safety and security [9]). The full variety of definitions can be experienced by using the apposite databases, for example, the ISO Online Browsing Platform (OBP) [10], DIN-TERMinology Portal [11], or the International Electrotechnical Vocabulary (IEV, IEC 60050), as provided by [12].

Inconsistencies of concepts, concept systems, and their terms will ultimately effect standards and related standards as compared to each other. It is therefore vital to create consistent concept systems in accordance with existing standardization activities and existing standards (cf. "Consequences of conceptual inconsistencies" section).

What is needed are means of mediation between standardization bodies that ensure real-time synchronization for convergent technologies, innovative concepts, and R\&D phase standardization. Synchronization tasks need to operate on a very fine-grained level while at the same time needing to remain an overview of the broader topics treated in the subject fields. As has been recognized for standardization of smart grids in general, steering groups for "inter-domain cooperation and coordination" are needed to avoid unnecessary efforts [6]. This should also be the case for efforts focusing on (or even only including) terminological issues. A respective coordination group could alleviate both problems by adding the relevant linguistic-methodical knowledge while at the same time having the overview over standardization efforts in different subordinate committees. Such groups could fulfill tasks of data governance, further disputes for settlement of concept- or term-related conflicts as well as assure formal or content-related data quality.

\section{Consequences of conceptual inconsistencies}

Terminology ambiguities are multidimensional and can bear serious consequences either for standardization organizations or for economic market and, in particular, for producing companies that develop and bring to the market their new technologies. For standardization bodies, it would cause a decreased product quality: ambiguous terminology will lead to ambiguous standards. In the area of economic market, it could have a negative impact on every step of the technology or innovation process. To present terminology-related problems with economic significance needs a rough division of this sector into its internal and external areas. Corporate internal area includes all activities needed for successful realization of a technology or innovation process: concept developing, product planning, system design, detail developing, product testing, production, and market launch. Activities of an external corporate sector include, by contrast, communication with business partners and customers, product marketing, distribution, logistic, delivering, and maintenance.

\section{Internal corporate sector}

In this sector, terminological ambiguities and duplicates can be caused by the division of labor between corporate departments. Due to company size, such differentiations lead to difficulties in managing currently ongoing company tasks resulting in an enormous lack of clarity. As a result, several different departments may simultaneously work on the same terminology without coordination with other departments [13]. Accordingly, many synonyms or homonyms will be introduced that, when added into central archives of internal technical documentation, will fossilize and the overall structure will be inconsistent. Such inconsistencies stay mostly unnoticed, until they cause significant loss events. Such inconsistencies can appear at every stage of a technology or innovation process and in every corporate department [14]. With regard to a development department, they could be the reason for undesirable developments. Cooperation of one department with production and manufacturing would cause terminological errors to spread which may be followed by manufacturing errors concerning the relevant products or technologies.

In such departments such as marketing or technical documentation that are responsible for development, creation, and subsequent dissemination of the technical documentation, terminological ambiguity could be the reason for inefficiency by management of documentation files: the ambiguities would be adopted into terminological databases, then be provided to technical editors for development of instructions for use, operating instructions or technical handbooks. It would reduce the efficiency of editor systems enormously and the quality of the text editing. According to the online survey of the Gesellschaft für Technische Dokumentation - tekom Deutschland e.V.-tekom e.V.- one to two thirds of all documentation errors are terminological errors [15].

Terminological ambiguity is also the most common cause of the reduction of work efficiency in sales departments. Managing of the synonymous or homonymous terminology could cause double warehousing or shortages as well as many wrong deliveries that dissatisfy customers and as a consequence impair corporate reputation [16].

The quality of internal corporate communication (which is conducted by use of company internal networks like intranet [17]) could also be influenced through inconsistent terminology. Search queries will 
be less resultful due to terminological variation that lessens the effectiveness of indexation. As a consequence, search queries deliver insufficient search results or wrongly select the requested information.

In the course of today's globalization, many corporations need to create multilingual intranet sites which provide contents from intranet sites in the language of the head office to corporate staff abroad. This should ensure that subject issues are communicated and understood professionally and in absolute equivalence in all corporate locations. As a consequence, the joint corporate internal knowledge network will be created which simplifies work-related cooperation.

The creation of terminologically well-managed corporate knowledge takes also place by further staff trainings in the form of specialized foreign language courses, because knowledge of foreign languages is one of the most important qualifications of every employee. Such education measures can bring poor results when learners use inconsistent specialized monolingual or bilingual dictionaries or glossaries which normally are the main terminological references for every language learner. In monolingual dictionaries/glossaries, such results are mostly caused by incorrectly determined meaning differences between synonymous, homonymous, or polysemous entries, which lead to difficulties of comprehension by dictionary users: by looking up a word, the user would not recognize the semantic side of the related entries and therefore would not be able to detect the meaning differences between them. This will result in the inability of the dictionary user to detect a correct usage environment (context) of the relevant synonyms and homonyms and misuse of terms in documentation and specifications. To solve this problem, other reference works like common word combination dictionaries need to be consulted. This, however, results in loss of efficiency and higher expenditure.

The fact that such monolingual dictionaries are mostly used by foreign language speakers makes important the detection of the exact semantic differences between synonyms and homonyms. As is known, many foreign language learners do not have the language intuition concerning semantic correctness about term combinatorics. Therefore, a wrong or inadequate information in such dictionaries could lead to incorrect term combinations, and memorizing could automatically lead to repeated misuse in the future.

Reaching terminological precision in bilingual dictionaries is essential for robust equivalence between terms of source and target languages. Every incorrect semantic relation between single synonyms and homonyms increases the probability to find incorrect equivalents in both languages. As a result of the fact that all terminological entries appear in such dictionaries without definitions, dictionary users cannot verify whether the semantic correctness of the foreign equivalence or the correctness of their usage environment is correct [18]. As a dictionary user, one thereby depends on term equivalence listed in the respective dictionary.

\section{External corporate sector}

The inconsistencies in source languages are the main causes of translation errors, like conceptual generalizations, specializations, alienation, or adaptation [19]. Therefore, one of the major communication problems caused by inconsistent terminology management occurs when translation services from a cooperative translation service provider must be requested [19].

False evaluation of the degree of synonymy in any source language can lead to limitations of term exchangeability and stylistic variability. Furthermore, partial synonyms may require different equivalent terms due to slight differences in meaning. Only when this fact is considered, valid equivalents can be found. Assuming absolute meaning equality between partial synonyms will lead to unreflecting use of equivalent terms and incorrect translations [20]. For example, a source text will describe some matter with a specific term while the target text uses a more general term. The semantic differentiations of the source text will be lost. Translations could also be made difficult by existence of homonyms in the source language. Allocation of many concepts to one term may prevent adequate translation because a translator may make the error of picking the wrong equivalent [15].

Regarding the translation process, inconsistent terminology will cause defects in the product as well as enormous time and cost losses. Increased needs of clarification and correction slow down decision-making and delay completion of translation assignments. Furthermore, it leads to defective terminology localization which at least makes necessary to repeat clarification situations permanently [21]. Localization is the process by which products and services are adapted to local peculiarities. This includes product documentation and its terminology. Localization of terminology encompasses cultural and technical assessment as well as linguistic and functional assurance. It should be presented in internal corporate glossaries and have ensured equivalence in foreign languages [22]. Using located terminologies by translation companies can therefore ensure a high-quality translation result.

Further defects can affect customer relationships established through sales or use of products or technologies. The main knowledge provider about operating instructions for products is technical documentation like operating instructions, manuals, etc. In such instructions, clear language and terminological consistency are the important feature for customer satisfaction: construction, use, 
and support for products heavily rely on clear communication. Product quality will be affected by defective corporate communication, and this again will affect the customers' disposition to identify with the brand.

In conformity with the German Civil Code and the German Product Liability Act, an instruction for use is an essential part of every product delivery and its creation is given the same importance and diligence like the remaining product components [23]. Based on this instruction liability, every instruction for use has to involve complete user instructions for every intended use, complete references to dangers, (residual) risks as well as foreseeable misuses of the relative products to ensure protection, and safety and health of the user [23]. "The right word at the right place at the right time" is, according to the European Commission, the condition for user safety [24]. The right word covers a clear and easy-tounderstand language. Incorrect product use caused by terminological misunderstandings is classified as product or instruction defects which can lead a user to lifethreatening situations. Fines may be imposed on manufacturers due to product liability, and prohibitions of marketing products may follow [13].

\section{Methods}

\section{Smart-grid-related glossaries}

Several glossaries currently under development in German standardization or taken from legal texts and authorities have been considered to assess whether these glossaries show violations of concept-orientation and whether they have conceptual overlap. The glossaries have mainly been chosen according to the criteria of relevance and availability. It must be taken into account that the presented terms and definitions are work in progress and may have changed during the course of the analysis. The glossaries taken into account have been provided by several sources relevant for the development of the smart grid but they are not exhaustive. Further glossaries are available but not considered here. The following glossaries have been considered:

- Glossaries of the German Bundestag as manifested by the German Renewable Energy Act [25] and the Energy Industry Act [26] [Bundestag] ${ }^{1}$

- Glossaries from the Metering System 2020 of the German Association for Electrical, Electronic and Information Technologies (VDE) [Meter]

- The smart grid glossary being developed by the working group 111.0.5 of the German Commission for Electrical, Electronic and Information Technologies (DKE) of DIN and VDE [DKE GAK 111.0.5]

- Glossaries from the German Standardization Roadmap for Electromobility by DKE [Electromobility]
- The glossary of working group DKE/GAK 914.0.3 functional safety of electrical/ electronic/ programmable electronic safety-related systems (E, E, PES) for the protection of people and the environment [GK 914] [27]

- Glossary of the open metering system group [28] [OMS]

- Glossaries from the DKE activities focused on smart home and building [SmartHomes]

The glossaries have been gathered from online sources and by requests to DKE. Groups then provided their glossaries for further processing. As mentioned above, concept orientation is a rather marginal issue for standardization bodies, so that terminological data are often presented with only a minimum of term-related or concept-identifying information:

1. Term

2. Definition or other short describing texts

3. Source

4. Alternative terms (equivalen(s), acronyms, other short forms, orthographical and non-orthographical variants, synonyms)

- Equivalent(s)

- Acronyms

- Other short forms

- Orthographical and non-orthographical variants

- Synonyms

5. Hyperonyms

Consider as an example the excerpts taken directly from the glossaries in Tables 1, 2, and 3.

Tables 1, 2, and 3 illustrate the diversity of the glossaries that are work products of standardization groups. Even though Table 1 shows a rather sophisticated approach in terminology data management, the spreadsheet shows vagueness and inconsistencies. For example, it shows the vague field "alternative entries" which is used for acronyms, full forms, and translations. Table 2 shows only an English term that is not only accompanied by an English but also by a German definition with a German equivalent missing. Table 3 shows that brackets are used inconsistently to establish relationships between entries. The explanation in row 1 could imply a relationship of synonymy while the definition in line 2 suggests a relationship of hyperonymy. The same holds for cells 1 and 2 in row 1 . Managing relationships between terms and concepts is a matter of ontology engineering or terminological ontology engineering (e.g., [29, 30, 31]).

The examples make apparent that there are violations as regards the ideal terminology standardization process as defined in [32]. Here, a strict procedure is stipulated that is outlined by three most basic tasks. A substantial 
Table 1 Glossary entries taken from [SmartHomes]

\begin{tabular}{|c|c|c|c|c|c|}
\hline Entry (ID) & Type & & Language & Definition & $\begin{array}{l}\text { Alternative } \\
\text { entries }\end{array}$ \\
\hline $\begin{array}{l}\text { Plug-in } \\
\text { electric } \\
\text { vehicles }\end{array}$ & Term & - & En & $\begin{array}{l}\text { A vehicle with an } \\
\text { electric drive } \\
\text { (as only drive or } \\
\text { in combination } \\
\text { with a fuel engine) } \\
\text { and a battery which } \\
\text { can be charged at } \\
\text { a charging station }\end{array}$ & PEV \\
\hline Consumer & Term & $\mathrm{n}$ & En & $\begin{array}{l}\text { End user of electricity, } \\
\text { gas, water, or heat. } \\
\text { The consumer can } \\
\text { also generate energy } \\
\text { using a distributed } \\
\text { energy resource }\end{array}$ & Letztverbraucher \\
\hline
\end{tabular}

methodological decision in this process is to work out concept systems separately for each language to be standardized. Only when all terms of all languages are structured conceptually, concept systems will be compared to find equivalents on the conceptual level. This means that "nach Möglichkeit die nationalen Systeme, die verschiedenen Organisationen, die verschiedenen Denkschulen usw. zu berücksichtigen sind" ${ }^{2}$ [32]. Practical terminology standardization, however, is lagging behind this methodology. The most obvious reasons being lack of time, lack of familiarity and "practice", and a stronger focus on the whole standard to be worked out. Here, not even concepts of one language are structured systematically. The transfer to other languages is then not characterized by comparison of concept systems but by the translation of single terms without a closer look at their context.

Nevertheless, in our analysis, all terms defined by the glossaries have been processed in the way they have been provided by the committees. They have been managed in a terminology management system as term-oriented entries (short: entries) that are accompanied by their additional data (definitions, sources, relations, status). This structure has been chosen to keep the autonomy of all glossaries and to process them descriptively while at the same time using them to prepare concept identification. Where given or identifiable, entries with alternative terms have been assigned to the (alleged, not yet confirmed) primary entry and each other by concept-termrelations. Here, we make use of additional relations that imply that the related entries have the same meaning but different terms and are therefore synonyms. These

Table 2 Glossary entries taken from [OMS-Group] [28]

\begin{tabular}{lll}
\hline Term & Description, English & Description, German \\
\hline Authentication & $\begin{array}{l}\text { Ensures the integrity of } \\
\text { the received data and } \\
\text { proves the declared origin }\end{array}$ & $\begin{array}{l}\text { Prüft Integrität (Richtigkeit) } \\
\text { und Ursprung der Daten }\end{array}$ \\
\hline
\end{tabular}

Table 3 Glossary entries taken from [Meter]

\begin{tabular}{|c|c|c|}
\hline Begriff & Erklärung & Quelle \\
\hline $\begin{array}{l}\text { Applikationsdaten } \\
\text { (Lokale Daten) }\end{array}$ & $\begin{array}{l}\text { Die TR } 03109 \text { verwendet } \\
\text { in einigen Textpassagen } \\
\text { den Begriff Applikationsdaten. } \\
\text { Aus Sicht des FNN-Lastenhefts } \\
\text { sind dies lokale Daten, die in } \\
\text { einem SMGw zum Zwecke des } \\
\text { Betriebes vorgehalten werden } \\
\text { müssen }\end{array}$ & $\begin{array}{l}\text { Lastenheft } \\
\text { SMGw } \\
\text { (Gateway, } \\
\text { Funktionale } \\
\text { Merkmale) }\end{array}$ \\
\hline $\begin{array}{l}\text { Tarifumschaltanweisung } \\
\text { (Steuersignal) }\end{array}$ & $\begin{array}{l}\text { Ein vom SMGW-Admin oder } \\
\text { von einem autorisierten CLS } \\
\text { übermittelte Anweisung für } \\
\text { dieSteuerung von Tari } \\
\text { fumschaltungen im SMGW }\end{array}$ & $\begin{array}{l}\text { Technische } \\
\text { Richtlinie BSI } \\
\text { TR-0310943 }\end{array}$ \\
\hline
\end{tabular}

relation types can accordingly be classified as synonymic but differ from general synonymy by giving additional information on the term or other parts of the related entries. These synonymic relations entail the following:

- Abbreviation: one entry is related to an entry with an abbreviated term for the concept (hasAbbreviation)

- Rejection: one entry is related to an entry with a synonymous but rejected term for the concept (hasRejected)

- Preference: one entry is related to an entry with a synonymous and preferred term for the concept (hasPreferred)

- Equivalence: one entry is an equivalent entry in another language (hasTranslation)

- Phrasal equivalence: one entry is related to an entry with an alternative but equivalent definition for the concept (hasEquivalentDefinition)

An example of such related entries is given in Fig. 4.

Figure 4 shows entries that have been related with each other according to the source glossaries. The relation types used are the synonymic relation types described above.

The population of these glossaries is as shown in Fig. 5.

\section{Identification of violations of concept-orientation and conceptual overlaps}

The investigated glossaries lack conceptual structuring so that the following procedure has been applied to identify violations and conceptual overlap:

Task 1: Term-duplicate analysis

1. Task 1.1: Glossary-internal term duplicate analysis

(a) Identifies occurrences of term duplications

(b) Gives simple criteria for quick classification of term duplications for the purpose of harmonization and merging of entries 


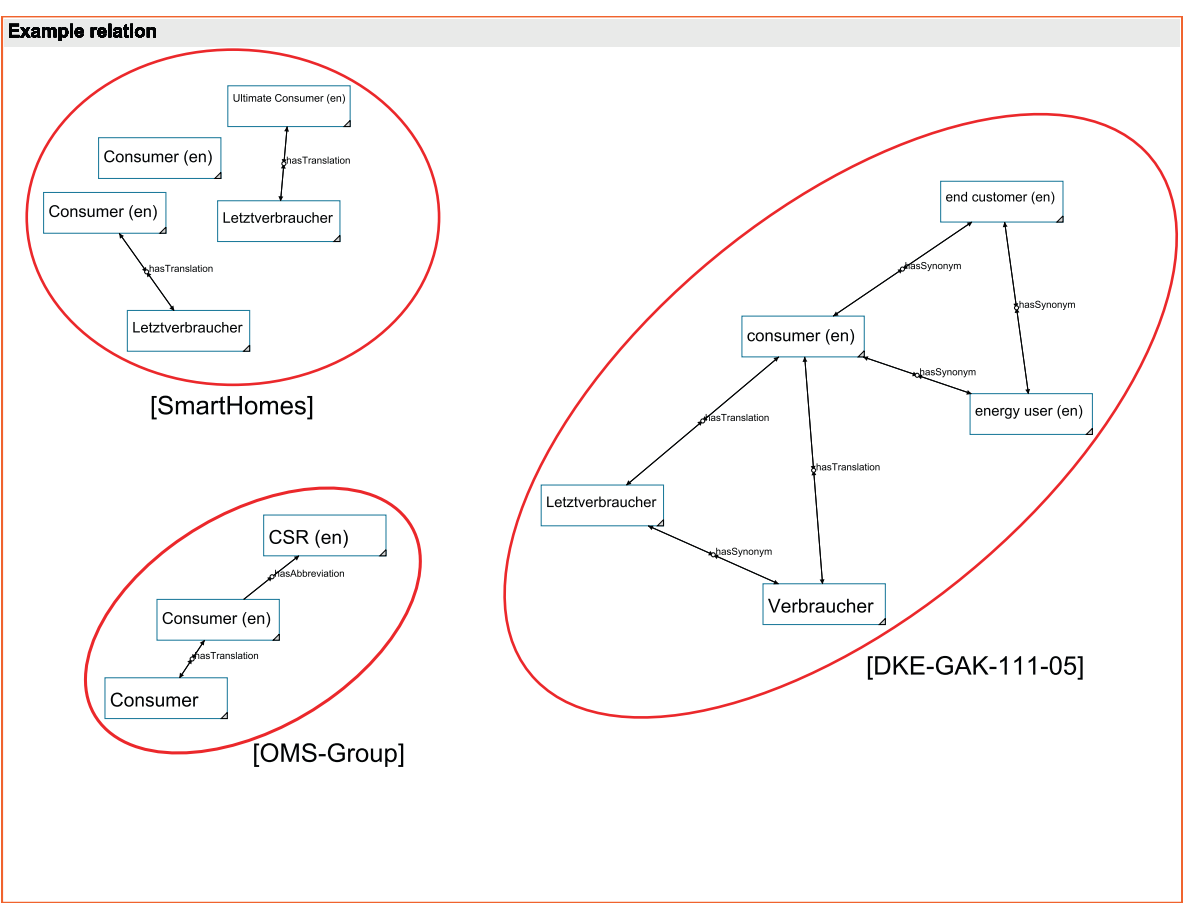

Fig. 4 Example relations

(c) Defines resulting actions for merging and harmonization

(d) Classifies term duplications and identifies resulting actions

(e) Makes recommendations for further actions to be performed by domain experts

2. Task 1.2: Glossary-extending term-duplicate analysis

Here, the same steps apply as in task 1.1.

Task 2: Synonym analysis

1. Task 2.1: Computer-aided synonym analysis

(a) Definition-duplicate analysis: identify definition duplicates

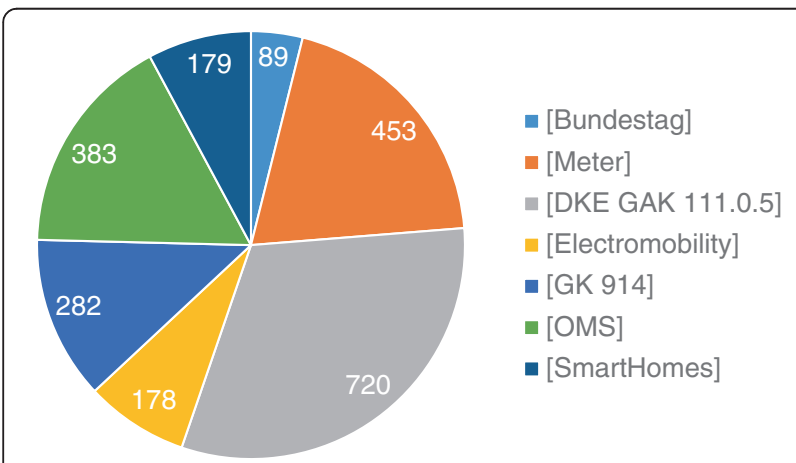

Fig. 5 Number of entries per glossary (b) Relation analysis: identify relevant relation types by analyzing metadata given in the source glossaries

(c) Harmonization and merging of entries

2. Task 2.2: Manual synonym analysis

(a) Pre-structuring of glossaries
(b) Concept comparison

\section{Results and discussion}

In the glossary analyses, the entries have been filtered and considered due to different criteria. The first entries to be analyzed were grouped by term (term-based entry groups in task 1). These entries varied in definition, source, or relations but had the same term. In the second analysis, entries were analyzed that were grouped by definition or by synonymic relations (task 2).

Task 1: term duplicate analysis

Task 1.1: summary of glossary-internal term duplicate analysis

Each glossary has been analyzed individually to identify glossary-internal occurrences of term duplication. This means that all entries labeled by the same term (= termbased entry groups) will be considered in the following descriptions. Yet undefined entries have been counted as well. The number of identified occurrences of term duplication for each glossary is listed in Fig. 6, thus representing an excerpt of the whole glossaries. 


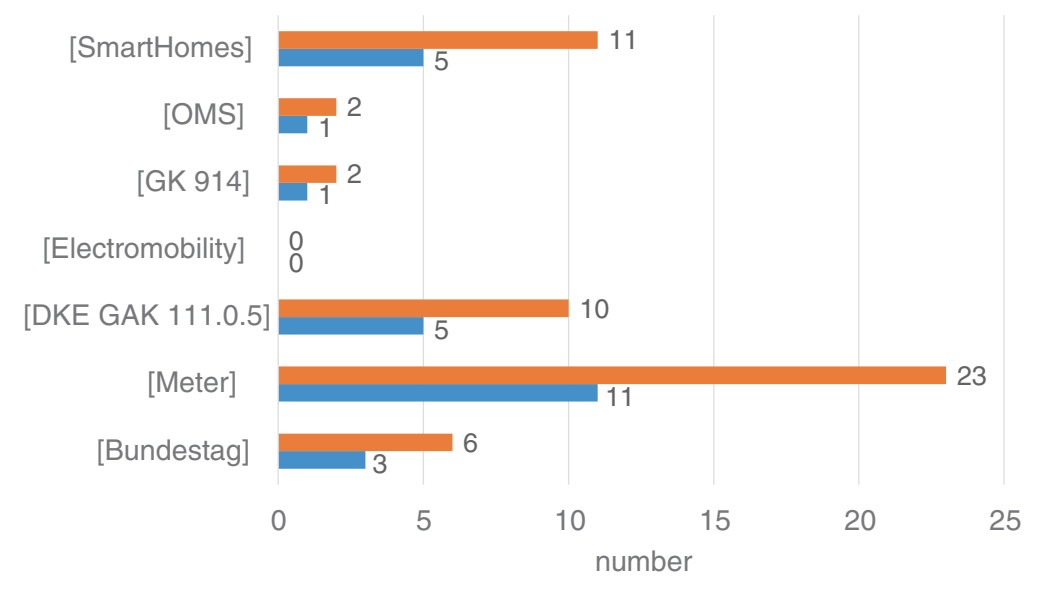

घ overall entries in term-based entry groups - term-based entry groups

Fig. 6 Number of glossary-internal occurrences of term duplication

The total number of term-based entry groups is 26 , with 54 entries involved. The terms under consideration here are $15 \%$ acronyms and $85 \%$ full forms.

The implications of the following analysis will be that the entries in term-based entry groups can be classified as either non-identical as regards their concepts (homonyms, polysemes) or as identical.

Figure 7 shows the number of entries in a term-based entry group for four examples with a full form term in the gray column. Next to it is the number of definitions in the orange column and the number of identical definitions in the blue column.

Table 4 gives several conditions for categorization of term duplications shown in Fig. 7 and some necessary actions that derive.
According to these criteria, every glossary entry can be classified for some necessary action that is a recommendation to domain experts. The plan of actions demonstrated in Table 5 results for each term-based entry group.

The identified occurrences of duplication for abbreviated terms, considered by the abovementioned glossaries and working groups, are shown by several examples in Fig. 8 . The blue column here shows the number of entries that are represented by the abbreviation given as the descriptor, the orange column says how many definitions these entries carry, the gray column shows whether these definitions are identical. The yellow and green columns refer to a different set of entries, i.e., those that are represented by the full term the abbreviated term stands for. The yellow column shows the number of all entries related to the abbreviated

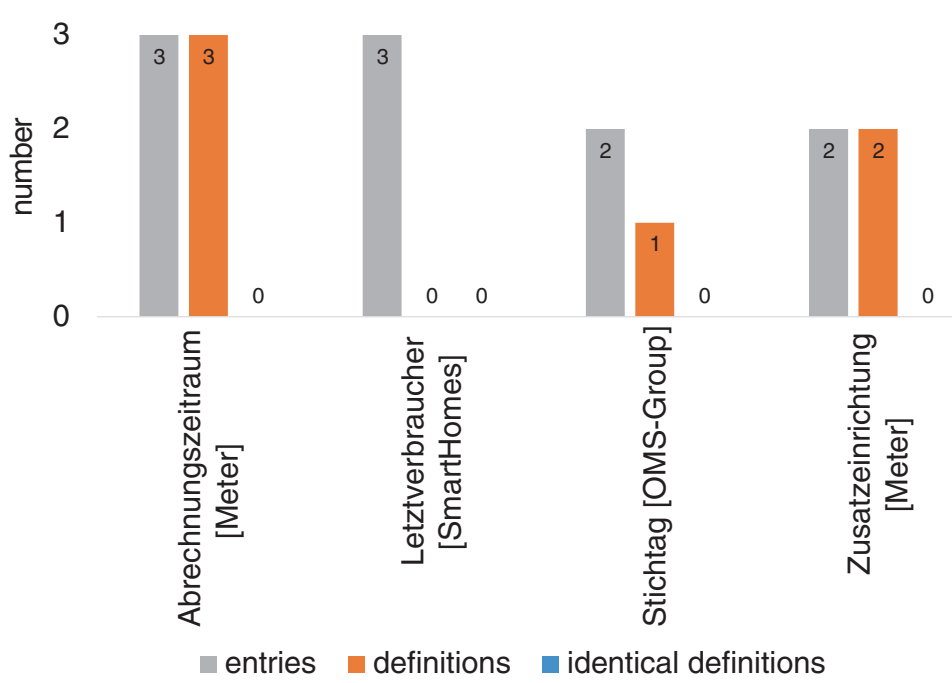

Fig. 7 Glossary-internal duplication of a selection of full form terms in smart-grid-related glossaries: opposition of number of entries and number of definitions of these entries 
Table 4 Conditions for the identification of necessary further actions for glossary-internal terminology standardization (full form terms)

\begin{tabular}{|c|c|c|}
\hline ID & Condition & Action \\
\hline 1 & $\begin{array}{l}\text { There is no definition within the respective glossary (e.g., } \\
\text { Letztverbraucher) }\end{array}$ & $\begin{array}{l}\text { An adequate definition for the glossary must be found, at best from an } \\
\text { existing source (including other glossaries under development) }\end{array}$ \\
\hline \multirow[t]{3}{*}{2} & \multirow{3}{*}{$\begin{array}{l}\text { There are less definitions than entries in the respective glossary } \\
\text { (e.g., Stichtag) }\end{array}$} & a) Duplicates need to be removed from the glossary \\
\hline & & $\begin{array}{l}\text { b) Undefined duplicates represent different concepts (homonymy) and } \\
\text { need to be defined accordingly }\end{array}$ \\
\hline & & c) Defined duplicates need to be treated according to action 3 \\
\hline \multirow[t]{4}{*}{3} & $\begin{array}{l}\text { There are as many definitions as entries in the glossary (e.g., } \\
\text { Zusatzeinrichtung) }\end{array}$ & $\begin{array}{l}\text { a) The definitions must be compared to see whether they are disjunct; } \\
\text { then the entries are homonyms and distinct preferred terms should be } \\
\text { determined where possible to help avoid misunderstandings }\end{array}$ \\
\hline & & $\begin{array}{l}\text { b) The definitions must be compared to see whether they are formally } \\
\text { identical; then the entries are conceptually identical and one of the } \\
\text { duplicates can be removed }\end{array}$ \\
\hline & & $\begin{array}{l}\text { c) The definitions must be compared to see whether they are semantically } \\
\text { identical: then the entries are conceptually identical, the preferred } \\
\text { definition must be determined and the duplicates can be removed }\end{array}$ \\
\hline & & $\begin{array}{l}\text { d) The definitions must be compared to see whether they overlap } \\
\text { semantically; then, the entries must be marked as polysemes }\end{array}$ \\
\hline 4 & $\begin{array}{l}\text { There are at least two definitions in the glossary and one } \\
\text { definition refers to the other definition(s) (e.g., } \\
\text { Abrechnungszeitraum) }\end{array}$ & $\begin{array}{l}\text { The reference implies identity so that the entries can be considered } \\
\text { conceptually identical and a merged entry could be created referencing } \\
\text { both sources of appearance }\end{array}$ \\
\hline
\end{tabular}

entries, while the green column shows the number of full form terms that are used to represent these entries.

We assume here that actions 1 to 4 have been performed beforehand and that the glossary-internal conceptual structure of full form entries is clear. Then, the following conditions can be distinguished and two types of actions can be derived as is shown in Table 6.

The abbreviation entries can be characterized as follows and a plan of action derives in Table 7 .

Which action needs to be taken may sometimes be a question of debate. Consider $L A N$ and its related full form term Local Area Network and the two entries for that term. The related full form entries describe similar concepts that vary in their degree of abstraction:

- Definition of entry 1: computer network located on a user's premises within a limited geographical area

- Definition of entry 2: Data communication network, connecting a limited number of communication

\section{devices (Meters and other devices) and covering a moderately sized geographical area within the premises of the consumer. In the context of this $P P$ the term LAN is used as a hypernym for HAN and $L M N$}

While one of them applies the definition of LANs given by IEC 60050 (IEV 732-01-04), the other is a very specific interpretation for application in smart grids. What needs to be determined is whether both should be represented by the same term and whether they represent the same concept or have a subordination relation. In the latter case, the distinction between subordinate and superordinate concept should be given by the term so that it has the capability of evoking the appropriate context. The same holds for its abbreviation.

The next section will show the overlaps that transcend the boundaries set by one glossary. Therefore, an analysis for term duplicates has also been conducted for all glossaries taken together.

Table 5 Resulting actions for glossary-internal terminology standardization (full form terms)

\begin{tabular}{|c|c|c|c|c|}
\hline Term-based entry group & Action \#1 & Action \#2 & Action \#3 & 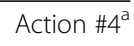 \\
\hline Abrechnungszeitraum [Meter] & & & $x$ & $x$ \\
\hline Letztverbraucher [SmartHomes] & $x$ & & & \\
\hline Stichtag [OMS-Group] & & $x$ & & \\
\hline Zusatzeinrichtung [Meter] & & & $x$ & $x$ \\
\hline
\end{tabular}

${ }^{a}$ Whether condition 4 can apply to a term-based entry group can easily be detected automatically, whether condition 4 does apply needs to be analyzed manually. 


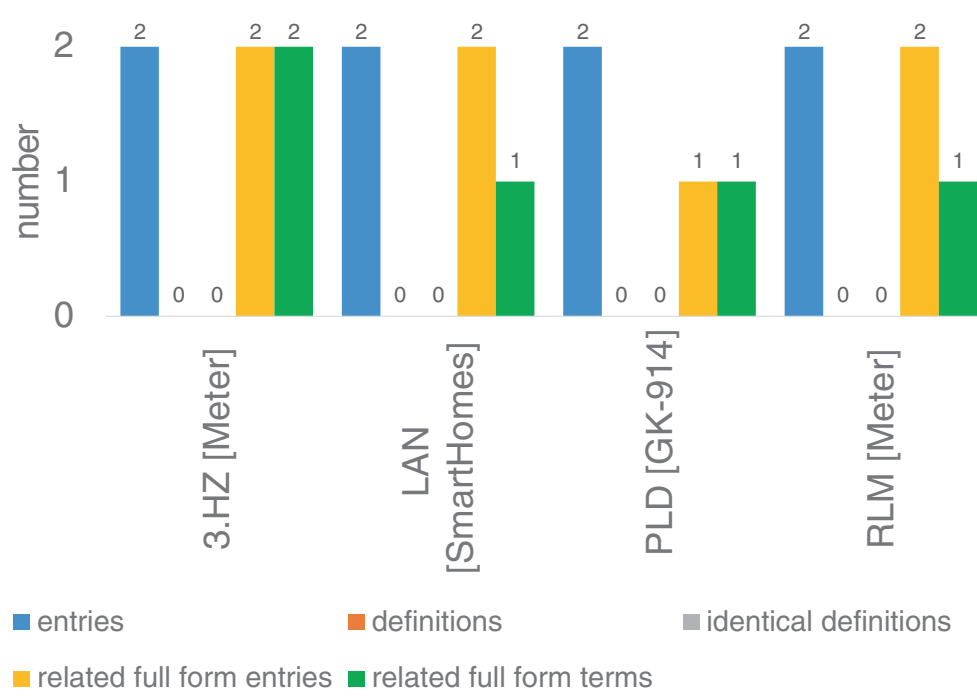

Fig. 8 The differentiation between full form entries and full form terms is made because different entries may be labeled with the same term so that there may be more related entries than terms. ${ }^{3}$

Task 1.2: summary of glossary-extending term duplicate analysis

In this analysis, 119 terms have been identified to occur more than once in several glossaries, representing 259 entries. The terms under consideration here are $36 \%$ acronyms, $61 \%$ full forms, and $3 \%$ mixed forms.

Figure 9 shows an excerpt of the term-based entry groups which have been identified in all glossaries taken together. The number of full form entries is shown in the blue column, next to the number of definitions used in these entries in the orange column, as well as the number of identical definitions in these term-based entry groups in the gray column.

Here again, criteria 1-4 can be distinguished (see "Task 1.1: summary of glossary-internal term duplicate analysis" section) so that the plan of action, shown in Table 8, results by classification of each term-based entry group.

Term duplication has also been identified for abbreviated terms of which again only an excerpt will be presented in this paper. Figure 10 shows the number of entries represented by the same abbreviation in the blue column, the number of definitions involved in these

Table 6 Conditions for the identification of necessary further actions for glossary-internal terminology standardization (abbreviations)

\begin{tabular}{lll}
\hline ID & Condition & Action \\
\hline 5 & The abbreviated forms & One of the abbreviation entries \\
represent the same concepts & can be removed from the glossary \\
6 & $\begin{array}{l}\text { The abbreviated forms do not } \\
\text { represent the same concepts }\end{array}$ & $\begin{array}{l}\text { Both abbreviation entries can be } \\
\text { maintained but their relationship } \\
\text { needs to be explicitly stated as } \\
\text { homonymy }\end{array}$ \\
\hline
\end{tabular}

term-based entry groups in the orange column, the number of identical definitions in the gray column, the number of related full form entries in the yellow column, as well as the number of related full form terms in the green column.

Here again, we assume that actions $1-4$ have been performed beforehand and that the inter-glossary conceptual structure is clear. Then, the following cases with according types of actions can be derived as shown in Table 9 .

The abbreviations listed here are interesting term duplications in several glossaries. The abbreviation entries themselves are already giving formal clues on their conceptual identity:

- Related full form terms are strongly hinting that different concepts are represented and homonymy applies (e.g., ERP for enterprise resource planning and effective radiated power)

- Related full form terms are orthographical variants so that the abbreviation entries are conceptually identical (e.g., HES for Head End System and Head-End System)

Table 7 Resulting actions for glossary-internal terminology standardization

\begin{tabular}{lll}
\hline Term-based entry group & Action \#5 & Action \#6 \\
\hline 3.HZ [Meter] & & $x$ \\
RLM [Meter] & $x$ & $x$ \\
PLD [GK-914] & $x$ & $x$ \\
LAN [SmartHomes] & $(x)$ & \\
\hline
\end{tabular}

Abbreviations: t.b.d. to be determined; $(x) \& x$ one action is more likely than the other; $x \& x$ both actions apply 


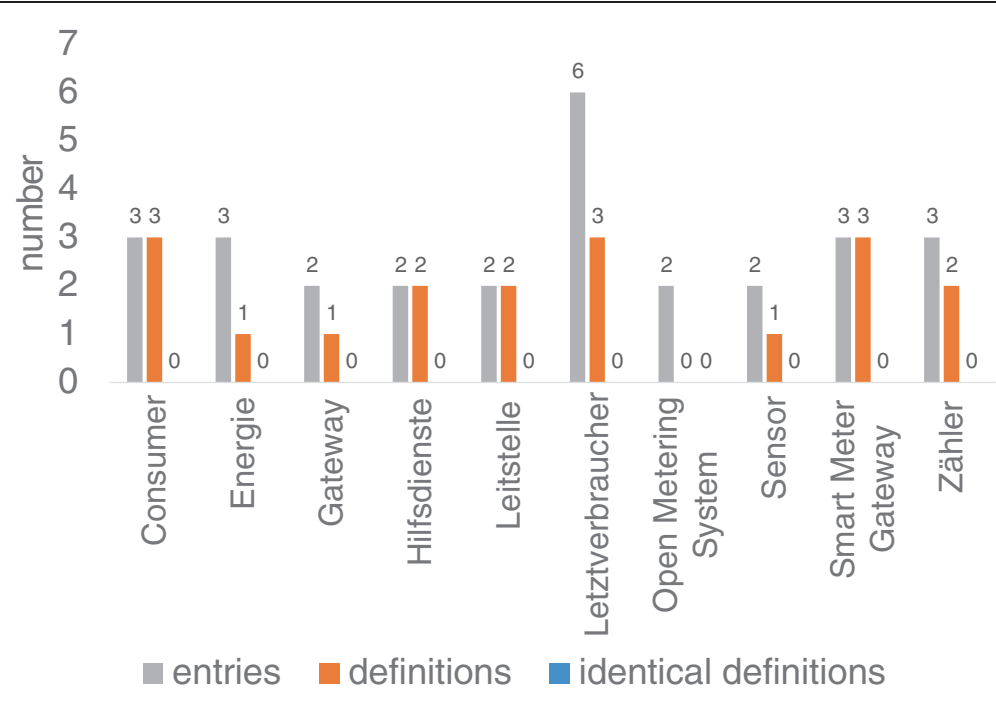

Fig. 9 Glossary-extending duplication of a selection of full form terms in smart-grid-related glossaries: opposition of number of entries and number of definition of these entries (full form terms)

- The full form terms suggest ontological differences that result in slightly different understandings while at the same time there is great formal similarity of the terms which leads to a high potential of misunderstanding (e.g., DER for distributed energy resource and Distributed Energy Resources where different conceptualizations may result from the singular/plural distinction)

- Their contexts or the contexts of their related full form entries may be different so that entries carry different semantic relations to other entries or show different viewpoints in their definitions and have different focuses; this makes it necessary to settle whether these are complementary views or whether they are conflicting (e.g., for KWK-Anlage)

- They or their related full form entries may reference different sources so that different conceptualizations are probable (e.g., OMS for open metering system)

Table 8 Resulting actions for glossary-extending terminology standardization (full form terms)

\begin{tabular}{|c|c|c|c|c|}
\hline Term-based entry group & Action \#1 & Action \#2 & Action \#3 & Action \#4 \\
\hline Consumer & & & $x$ & $x$ \\
\hline Energie & & $x$ & & \\
\hline Gateway & & $x$ & & \\
\hline Hilfsdienste & & & $x$ & $x$ \\
\hline Leitstelle & & & $x$ & $x$ \\
\hline Letztverbraucher & & $x$ & & $x$ \\
\hline Open metering system & $x$ & & & \\
\hline Sensor & & $x$ & & \\
\hline Smart meter gateway & & & $x$ & $x$ \\
\hline Zähler & & $x$ & & $x$ \\
\hline
\end{tabular}

While the performance of task 1 primarily serves to identify homonymy of terms, it will also lead to the identification of conceptually identical entries. However, not all instances of conceptual identity can be identified by task 1 . Therefore, task 2.1 and task 2.2 need to be performed additionally.

Task 2: synonymy identification in smart-grid-related glossaries: glossary-internal and glossary-extending analysis Task 2.1: computer-aided synonymy identification

Synonyms have been identified by comparing two data categories of the glossaries:

1. The text of their definitions

2. Semantic relations of certain types (based on metadata analysis in the original glossaries, e.g., brackets, additional columns, and definition comparison)

In total 255 synonym entries have been identified (cf. Fig. 11).

For inter-glossary comparison based on relations, only those entries have been considered where the relation's subject and object are located in distinct glossaries. Since the glossaries so far have been tended separately, there are no inter-glossary relations. Furthermore, the glossaries are concerned with new terminology: although a recourse to existing terminologies could be possible to integrate known terms, it is not likely that these are the first documented terms in the different glossaries. Hence, identical definitions are not to be expected in the current stage of the glossaries. In summary, there are no inter-glossary synonyms. 


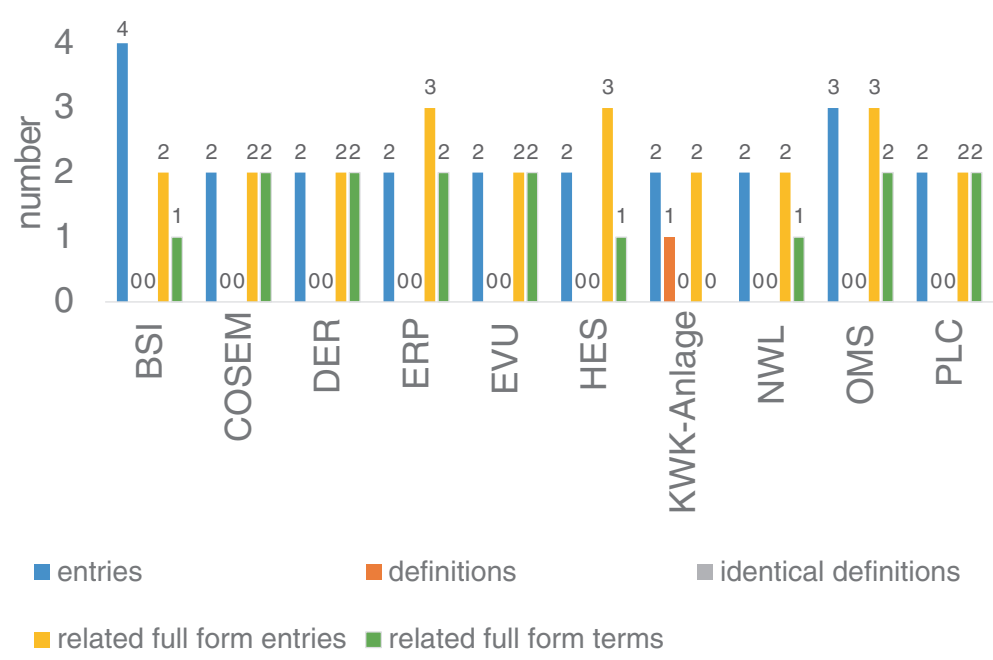

Fig. 10 Glossary-extending duplicates of abbreviations in smart-grid-related glossaries: opposition of number of full form entries, definitions, identical definitions, and related full form entries and related full form terms

For glossary-internal comparison, the occurrence of identical definitions and glossary-internal relations is much higher. Standardization groups are well aware of the non-bijective relationship of terms and concepts but do not explicitly manage these relations in their glossaries. The relations that helped to identify the synonyms are therefore based on spreadsheet data (see "Smart-grid-related glossaries" section). The explicit marking of synonymies should be conducted.

Table 10 shows a selection of synonym sets that have been identified by comparison of definition.

Table 11 shows a selection of synonym sets that have been identified by synonymic relations.

To be normative, synonyms need to be classified according to their permission for use: are they preferred, deprecated, or permitted? When several abbreviations are synonyms, then the abbreviation of the preferred

Table 9 Resulting actions for glossary-internal terminology standardization

\begin{tabular}{lll}
\hline Term-based entry group & Action \#5 & Action \#6 \\
\hline BSI & $x$ & $x$ \\
COSEM & $x$ & $(x)$ \\
DER & $x$ & $x$ \\
ERP & $x$ & $x$ \\
EVU & t.b.d. & $x$ \\
HES & t.b.d. & $(x)$ \\
KWK-Anlage & $x$ & t.b.d \\
NWL & $x$ & t.b.d. \\
OMS & x & $x$ \\
PLC & (x) \\
\hline
\end{tabular}

Abbreviations: t.b.d. to be determined; $(x) \& x$ one action is more likely than the other; $x \& x$ both actions apply related full form term should be chosen as preferred abbreviation. Analogically, abbreviations of deprecated full form terms should be deprecated as well.

Task 2.1 does not identify all cases of synonymy since it is only based on relations and formal identity of definitions. When definitions are not identical or entries are not related, there will be no findings, which is why task 2.2 needs to be applied as well. This, however, requires thorough study of sources.

\section{Task 2.2: manual synonymy-identification}

Since naturally growing terminologies will contain synonymy, a certain approach to terminology work needs to be followed to identify synonymic relations among entries with identical terms. This approach is for example described by [23, 32, 33]. Systematic terminology work is corpus-based: from relevant sources of a domain, term candidates (= primary information) and terms' meanings, uses, grammatical categories etc. (= secondary information) will be drawn. Potential terms are, in this process, supposed to be administered as term-based entries that include the secondary information. Alternative terms should only then be included to such term-based entries when they are abbreviations or orthographical variants. Alleged synonyms should be treated autonomously.

The information taken from the corpus is then instrumentalized by the terminologist in order to aid the reconstruction of the domain's conceptual system. Information on the terms' meanings (definition-like information on the characteristics of a concept) will be considered to identify the concept-term-relations. Accordingly, term-based entries will be allocated to their common concept and synonymic relations will be established. The comparison of concept systems of different 


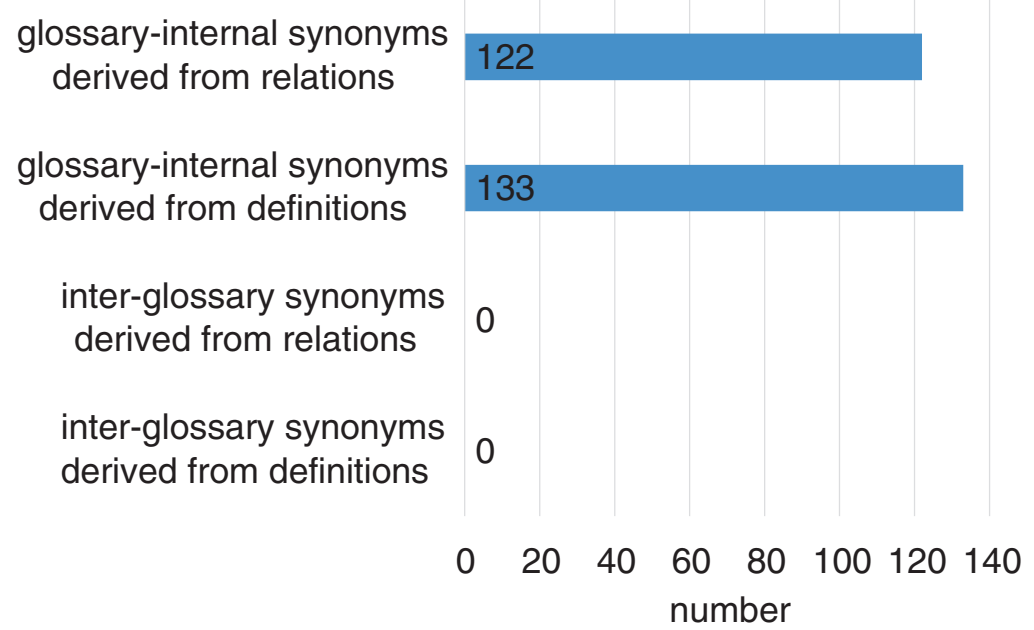

Fig. 11 Overview over synonymous entries in all glossaries

languages should proceed one concept at a time, so that a common structure can be uncovered.

The terminological literature makes very clear that the reconstruction of monolingual concept systems should be complete before the establishment of equivalence relations begun (especially emphasized by [2]). This also requires that each concept of a language must be fully defined. Picht et al. [2] recommends that the identification of synonyms needs to be confirmed by reliable sources, which include oral statements of domain experts. Going one step further, it will even become necessary to clear contradictory information with an expert who is sufficiently authorized to do this, before equivalence between systems is established. The comparison of concept systems with the aim of finding equivalents and probably even the adjustment of concept positions, and therefore systems, is then based on the comparison of definitions that describe characteristics of concepts. Equivalence relations should only be documented when conceptual identity is firmly identified.

Table 10 Selection of synonym entries identified by comparison of definitions given by source glossaries

\begin{tabular}{|c|c|c|c|}
\hline $\begin{array}{l}\text { Set } \\
\text { ID }\end{array}$ & Glossary & Synonyms & Definitions \\
\hline \multirow[t]{2}{*}{3} & \multirow[t]{2}{*}{ Meter } & Steuersignal & \multirow{2}{*}{$\begin{array}{l}\text { Eine vom SMGW-Admin oder von einem autorisierten CLS übermittelte Anweisung } \\
\text { für die Steuerung von Tarifumschaltungen im SMGW }\end{array}$} \\
\hline & & Tarifumschaltanweisung & \\
\hline \multirow[t]{4}{*}{4} & \multirow[t]{4}{*}{ Elektromobilität } & Ladestation & \multirow{4}{*}{$\begin{array}{l}\text { Eine Ladestation ist ein zum Laden von Elektrofahrzeugen vorgesehenes Betriebsmitte } \\
\text { gemäß IEC 61851, das als wesentliche Elemente die Steckvorrichtung, einen } \\
\text { Leitungsschutz, eine Fehlerstrom-Schutzeinrichtung (RCD), einen Leistungsschalter } \\
\text { sowie eine Sicherheits-Kommunikationseinrichtung (PWM) enthält. Abhängig vom } \\
\text { Einsatzort können ggf. noch weitere Funktionseinheiten wie Netzanschluss und } \\
\text { Zählung hinzukommen. Die DIN EN 61851-1 (VDE 0122-1) definiert die Begriffe } \\
\text { "Wechselstrom-Ladestation für das Elektrofahrzeug" und "Gleichstrom-Ladestation } \\
\text { für das Elektrofahrzeug". In der Normungs-Roadmap wird auch der Begriff } \\
\text { Ladestation daher als Oberbegriff verwendet und schließt AC-, DC- und das } \\
\text { induktive Laden ein }\end{array}$} \\
\hline & & Stromversorgungseinrichtung & \\
\hline & & für das Elektrofahrzeug & \\
\hline & & & \\
\hline \multirow[t]{3}{*}{5} & \multirow[t]{3}{*}{ GK-914 } & Application data & \multirow{3}{*}{$\begin{array}{l}\text { Part of the software of a programmable electronic system that specifies the } \\
\text { functions that perform a task related to the EUC rather than the functioning } \\
\text { of and services provided by the programmable device itself }\end{array}$} \\
\hline & & Application software & \\
\hline & & Configuration data & \\
\hline \multirow[t]{2}{*}{7} & \multirow[t]{2}{*}{ OMS-Group } & Eichwesen & \multirow[t]{2}{*}{ Messung im geschäftlichen oder amtlichen Verkehr } \\
\hline & & Gesetzliches Messwesen & \\
\hline \multirow[t]{3}{*}{24} & \multirow{3}{*}{$\begin{array}{l}\text { DKE-GAK-111- } \\
0-5\end{array}$} & Cumulating measuring unit & \multirow{3}{*}{$\begin{array}{l}\text { Instrument intended to measure energy quantities by integrating power } \\
\text { with respect to time }\end{array}$} \\
\hline & & $\begin{array}{l}\text { Measuring device for supplied } \\
\text { quantities }\end{array}$ & \\
\hline & & Meter & \\
\hline
\end{tabular}


Table 11 Selection of synonym entries identified by synonymic relations based on source glossary meta-data

\begin{tabular}{|c|c|c|c|}
\hline Set ID & Glossary & Synonyms & Definitions \\
\hline \multirow[t]{3}{*}{71} & \multirow[t]{3}{*}{ DKE-GAK-111-0-5 } & Anforderungsseitige Führung & \multirow{2}{*}{$\begin{array}{l}\text { Anwendungsfallszenario als Prozess, das den Versorger befähigt, in Notsituationen } \\
\text { oder im geplanten Betrieb die Anforderungskurve zu managen und die } \\
\text { Kunden-Lastkurve zu bestimmen, wobei die Funktionen die Laststeuerung } \\
\text { und die Lasterhebung beinhalten }\end{array}$} \\
\hline & & \multirow[t]{2}{*}{ Demand side management } & \\
\hline & & & $\begin{array}{l}\text { Funktion, die den Versorger befähigt, in Notsituationen oder im geplanten } \\
\text { Betrieb die Anforderungskurve zu managen und die Kunden-Lastkurve zu } \\
\text { bestimmen, wobei die Funktionen die Laststeuerung und die Lasterhebung } \\
\text { beinhalten. }\end{array}$ \\
\hline \multirow[t]{5}{*}{84} & \multirow[t]{5}{*}{ DKE-GAK-111-0-5 } & Komponente & \multirow{5}{*}{$\begin{array}{l}\text { Erzeuger von elektrischer Energie oder Wärmeenergie über zentrale } \\
\text { Erzeugungsanlagen. verteilte Erzeugunganlagen sowie Mikroerzeugung } \\
\text { in den Objektnetzen der Prosumer }\end{array}$} \\
\hline & & Technischer Akteur & \\
\hline & & Systemelement & \\
\hline & & Aktor & \\
\hline & & Systemkomponente & \\
\hline
\end{tabular}

$102 \quad$ Meter $\quad \begin{aligned} & \text { Abrechnungszeitraum } \\ & \text { Abrechnungsturnus }\end{aligned}$

\begin{abstract}
Der Abrechnungszeitraum legt die Start- und Endezeitpunkte des Zeitraums fest, über den eine Abrechnung erstellt wird. Ein SMGW kann diese, vertragliche Größen nicht kennen, da der Endezeitpunkt erst dann bekannt sein wird, wenn ein Letztverbraucher seinen Vertrag kündigt oder ändert. Hingegen kann ein SMGW den Abrechnungsturnus (jährlich, vierteljährlich, monatlich) kennen. Im Sinne der TR-Zielsetzung wird daher angenommen, dass der Abrechnungsturnus gemeint ist, wenn die TR den Begriff "Abrechnungszeitraum" benutzt.

Der Abrechnungszeitraum legt die Start- und Endezeitpunkte des Zeitraums fest, über den eine Abrechnung erstellt wird. Ein SMGW kann diese, vertragliche Größen nicht kennen, da der Endezeitpunkt erst dann bekannt sein wird, wenn ein Letztverbraucher seinen Vertrag kündigt oder ändert. Hingegen kann ein SMGW den Abrechnungsturnus (jährlich, vierteljährlich, monatlich) kennen. Im Sinne der TR-Zielsetzung wird daher angenommen, dass der Abrechnungsturnus gemeint ist, wenn die TR den Begriff Abrechnungszeitraum benutzt.
\end{abstract}

The methodological consequence is that terminology work needs to include some sort of redundancy when it comes to the description of meaning: each term going into the concept comparison needs to contain information elements that serve to identify the concept and help decide whether two terms represent the same concept.

Summing up, the approach taken to reconstruct a concept system is based on information extracted from original domain sources, comparison of this information, descriptions of defining characteristics of concepts and fully formulated definitions. This is a very sound methodology for concept reconstruction that will take into account cultural, historical, and idiosyncratic features of a domain's concept system as well as contradictions and controversies of the domain.

There are, however, several drawbacks with this approach: first, the information extracted from the context may be irrelevant for the identification and description of the concept that is represented by the term. Second, comparability of concepts may be restricted due to several factors: a concept may not be reconstructed properly (underrepresentation), it may be represented from different perspectives, there may be a discrepancy on the amount of information in the term entries that represent the concept, and there may be different arrangements of style and information structure (which would be especially relevant for computer-aided comparison). Third, the corpus may not give any explicit hints on synonymic or homonymic relations between terms so that the ambiguities of the corpus texts may be transferred to the terminology. Fourth, the term-by-term-comparison is very time-consuming and expensive.

To conclude, the question whether term-based entities are to be related by conceptual identity is not easily decidable. For terminology standardization, efforts of pairwise comparison should be lessened, either methodically or automatically to make the whole procedure more economically feasible.

A feasible way to enhance comparability of (preliminary) definitions is the application of standards for information structuring. Information units needed to identify conceptual identity of terms can thus be organized according to common principles. A common standard for definitions is DIN 2342:2011-08, which gives recommendations on how to write definitions. A common template would enhance machine comparability of definitions. This, however, would require terminological rigor also in definitions. Other possibilities of information comparison could be provided by natural language processing techniques, identifying common semantic structures in definitions, preliminary definitions and secondary 
information extracted from documents. Methodologically, a pre-structuring of the terminologies may help reduce the number of comparison pairs for which formal or semantic criteria could be applied. The question as to what kind of criteria (e.g., compositional structure of terms) should be applied and how to identify them for a specific domain is, however, left to future work.

Task 2.1 and task 2.2 give proposals for mergeable entries. Experts need to agree or disagree with these proposals, and in case of disagreement, they need to start a process of clearing and settlement between working groups, not just within their own working group. When this has been done, common entries should be merged from the ones existing in working-group-specific glossaries. The end of the process would be a common terminological resource during the process of its development.

\section{Conclusions}

This article has shown how terminology standardization for smart grids produces overlapping glossaries that may contain different concept systems and contradictory definitions. A reason for this can be seen in the practical impossibility for domain experts to reach a high level of methodological practice as regards terminology management. Furthermore, the situation is complicated by the fact that standardization committees may even start out with preliminary terminology that is prone to changes and may consolidate outside the committees. Despite ongoing efforts to deal with convergence in standardization and coordination of standardization bodies by expertise centers and steering committees, the measures undertaken are not fully effective on the terminological level. There are overlaps between the glossaries that are in need of inter-committee harmonization.

To reach truly standardized terminology resources, it is necessary to include terminological experts into working groups and to reach an overall gain in efficiency for the task of identifying concept-term-relations of heterogeneous domain-specific sources and glossaries from standardization bodies. There should be better assistance for domain experts that participate in standardization and the task of glossary data management. Data governance mechanisms for standardized terminologies and terminologies currently being standardized could be helpful, probably in the form of a coordination group trained in linguistics and terminology methods.

The article shows a structured way of identifying common terminological problems like homonymy and synonymy and a fine-grained method for treating these phenomena on the concept and term level, where they appear. The method leads to proposals that can be put to vote among domain experts. This is exemplified by data from smart-grid-related glossaries currently under development. The identification of glossary elements that represent the same concept in several of the glossaries under development is necessary to overcome the boundaries of single working groups. When identified, those concepts should be treated as a common resource of the whole domain which makes it necessary to provide it as such to the interested parties. The single entries of the glossaries could be-after harmonization-merged to a single resource that is based on wider consensus among working groups during the process of development.

For the purpose of the analysis, all glossaries have been transferred to a common platform, a terminology management system prototype [34] of TU Braunschweig. This or a like common web-platform could be used for further development and synchronization of the glossaries, as well as for definitions of conceptual systems with explicit concept relations. Respective tools for published terminologies are already in use, e.g., ISO Online Browsing Platform (OBP) [10], DIN-TERMinology Portal [11], or the International Electrotechnical Vocabulary (IEV, IEC 60050), as provided by [12], which are the most valuable resources for terminology development. In our approach to bring together different glossaries under development, we furthermore started a process of establishing ontologically structured systems, which has most prominently been adopted in DKE/GAK 111.0.5. In such systems, inconsistencies can be more easily detected and common areas of definition activities can be detected. The resulting data can furthermore be brought into semantic applications, e.g., for information retrieval.

\section{Endnotes}

${ }^{1}$ In the following, all glossaries will be referenced by short reference given in square brackets.

${ }^{2}$ Translation by the authors: if possible, national systems, different organizations and different schools and practices etc. need to be considered.

\section{Competing interests}

The authors declare that they have no competing interests.

\section{Authors' contributions}

SA conducted the analysis of the glossary data and devised the structure of the paper and is responsible for the final draft. TS conducted the literature review, drafted the backgrounds section of the paper, and gave critical reviews on the analysis sections of the draft. CG conducted a review of the complete paper for English language, contents, and comprehensibility of the paper. All authors read and approved the final manuscript.

\section{Authors' information}

SA is a research associate at the Institute for Traffic Safety and Automation Engineering of TU Braunschweig. Her research topics are located in special language communication: (1) terminology in requirements engineering and standardization, (2) terminologies as ontological structures, and (3) term formation and intuition.

TS is a research associate at Germany's National Metrology Institute Physikalisch-Technische Bundesanstalt in Braunschweig. Her research topics are language for special purposes: understandability of words and texts, language use in technical contexts.

CG is a research associate and postgraduate at the working group Networks and Distributed Systems at Faculty of Technology at Bielefeld University. His 
research topics are terminological requirements in standardization and system safety and security.

\section{Acknowledgements}

This paper has been made possible by funding from the Federal Republic of Germany for the SmartTerms project. The funding body is the Federal Ministry for Economic Affairs and Energy (BMWi). A critical review for the paper has been given by Dr.-Ing. Uwe Becker of TU Braunschweig, Institute for Traffic Safety and Automation Engineering. A part of the analyzed glossaries has been provided by working groups from the Deutsche Kommission Elektrotechnik Elektronik Informationstechnik in DIN und VDE, Verband der Elektrotechnik Elektronik Informationstechnik e.V. or have been taken from publicly available Federal Publications or publications from OMS-Group. We very much want to thank them for giving insights to preliminary working products.

\section{Author details}

${ }^{1}$ Institut für Verkehrssicherheit und Automatisierungstechnik, Technische Universität Braunschweig, Hermann-Blenk-Straße 42, 38108 Braunschweig, Germany. ${ }^{2}$ Physikalisch-Technische Bundesanstalt, Bundesallee 100, 38116 Braunschweig, Germany. ${ }^{3}$ AG Rechnernetze und verteilte Systeme, Universität Bielefeld, Universitätsstraße 25, 33615 Bielefeld, Germany.

Received: 12 February 2015 Accepted: 11 June 2015

Published online: 01 July 2015

\section{References}

1. Deutsche Kommission Elektrotechnik Elektronik Informationstechnik im DIN und VDE (DKE) (2013) Die Deutsche Normungs-Roadmap Smart Home + Building: Status, Trends und Perspektiven des Smart Home + BuildingNormung., https://www.dke.de/de/std/informationssicherheit/documents/ nr_smart\%20home_de_version\%201.0.pdf. Accessed 10 Feb 2015.

2. Picht H, Arntz R, Schmitz K-D (2014) Einführung in die Terminologiearbeit. Olms, Hildesheim

3. Sucharowski W (2009) Die Normierbarkeit der Kommunikation. In: Henn-Memmesheimer B, Franz J (eds) Die Ordnung des Standard und die Differenzierung der Diskurse: Akten des 41. Linguistischen Kolloquiums in Mannheim 2006, Teil 1. Peter Lang, Frankfurt am Main

4. Wendt S (1997) Terminus - Thesaurus - Text: Theorie und Praxis von Fachbegriffssystemen und ihrer Repräsentation in Fachtexten. Narr, Tübingen" 1204-1205 - change "Das neue produktsicherheitsgesetz (prodSG): leitfaden fur hersteller

5. International Standardization Organization (2007) ISO 860:2007: Terminology work - harmonization of concepts and terms. ISO, Geneva

6. Deutsche Kommission Elektrotechnik Elektronik Informationstechnik im DIN und VDE (DKE) (2013) The German roadmap E-energy/smart grid 2.0., German Version: https://www.dke.de/de/std/aal/documents/nr eenergy\%20smart\%20grid_de_version\%202.0.pdf; English Version: https:// www.dke.de/de/std/excellenceclustersmartenergy/aktivit\%C3\%A4ten/documents/nr_eenergysmart\%20grid_en_version_2.0.pdf. Accessed 16 Oct 2014

7. Deutsches Institut für Normung (n/a) DIN-leaflet for R\&D phase standardization. http://www.ebn.din.de/sixcms_upload/media/2929/EBNBroschuere.pdf. Accessed 01 Dec 2014

8. Deutsche Kommission Elektrotechnik Elektronik Informationstechnik im DIN und VDE (DKE) (2013) The German standardization roadmap for electromobility - version 2.0A., German Version: http://www.dke.de/de/std/ aal/documents/nr_elektromobilit\%C3\%A4t_de_version\%202.0a.pdf, English Version: http://www.dke.de/de/std/aal/documents/nr_elektromobilit\%C3\% A4t_en_version\%202.0a.pdf. Accessed on 26 Oct 2014

9. Piètre-Cambacédès L, Chaudet C (2010) The SEMA referential framework: avoiding ambiguities in the terms "security" and "safety". Int J Crit Infrastruct Prot 3(2):55-66. doi:10.1016/j.ijcip.2010.06.003

10. Online Browsing Platform. [www.iso.org/obp]

11. DIN-TERMinology Portal. [www.din-term.din.de]

12. International Electrotechnical Vocabulary. [www.electropedia.org]

13. Loetzer M, Buck P, Schwabediessen A (2013) Rechtskonformes Inverkehrbringen von Produkten: In 10 Schritten zur Konformitätserklärung. Beuth, Berlin u. a

14. Kalogerakis K (2010) Innovative Analogien in der Praxis der Produktentwicklung. Gabler, Wiesbaden
15. Schmitz K-D, Straub D (2010) Erfolgreiches Terminologiemanagement im Unternehmen. Grundlagen, Umsetzung, Kosten-Nutzen-Analyse, Systemübersicht. TC and more GmbH, Stuttgart, Praxishilfe und Leitfaden

16. Budin G (1996) Wissensorganisation und Terminologie: Die Komplexität und Dynamik wissenschaftlicher Informations- und Kommunikationsprozesse. Narr, Tübingen

17. Bodrow W, Bergmann P (2003) Wissensbewertung in Unternehmen: Bilanzieren von intellektuellem Kapital. Erich Schmidt Verlag GmbH \& Co KG, Berlin

18. Model BA (2010) Syntagmatik im zweisprachigen Wörterbuch. Walter de Gruyter, Berlin, New York

19. Stegemann J (1991) Übersetzung und Leser: Untersuchung zur Übersetzungsäquivalenz, dargestellt an der Rezeption von Multatulis "Max Hevelaar". de Gruyter, New York

20. Langenmayr A (1997) Sprachpsychologie. Ein Lehrbuch. Hogrefe, göttingen u. A

21. Körper D (2007) Terminologie in der Softwarelokalisierung - Probleme und Lösungen. Diplomatica Verlag, Hamburg

22. SDL (2014) Software localization: what is software localization?., http://www.sdl.com/technology/language-technology/what-is-softwarelocalization.html. Accessed 07 Dec 2014

23. Schlagowski H (2013) Technische Dokumentation im Maschinen- und Anlagenbau: anforderungen. Beuth, Berlin

24. Wilrich T (2012) Das neue Produktsicherheitsgesetz (ProdSG): Leitfaden für Hersteller. Importeure und Händler, Beuth, Berlin

25. Erneuerbare-Energien-Gesetz vom 21. Juli 2014 (BGBI. I S. 1066), das durch Artikel 4 des Gesetzes vom 22. Juli 2014 (BGBI. I S. 1218) geändert worden ist.

26. Energiewirtschaftsgesetz vom 7. Juli 2005 (BGBI. I S. 1970, 3621), das zuletzt durch Artikel 6 des Gesetzes vom 21. Juli 2014 (BGBI. I S. 1066) geändert worden ist.

27. International Electrotechnical Commission (IEC) (2010) IEC 61508-4:2010 Functional safety of electrical/ electronic/ programmable electronic safetyrelated systems - part 4: definitions and abbreviations. IEC, Geneva. German version: DIN EN 61508-4:2011-02 funktionale sicherheit sicherheitsbezogener elektrischer/ elektronischer/ programmierbarer elektronischer systeme teil 4: begriffe und abkürzungen. Beuth, Berlin

28. OMS Group (2014) Open metering system specification. Glossary of terms used in or related to the OMS annex A to volume 1 general issue 2.0.0. FINAL DRAFT A (2014-01-27)., http://oms-group.org/download4all/. Accessed 01 Mar 2014

29. Stein C (2012) Terminologie-Ontologien im Einsatz: über Missverständnisse unter Experten und Methoden zu einem besseren Verstehen. In: Jumar U, Schnieder E, Diedrich C (eds) EKA 2012: Entwurf Komplexer Automatisierungssysteme 2012. ifak, Magedeburg, p 321

30. Stein C (2012) Von der Terminologie zum semantischen Netz: Wissensmanagement und Ontologien. In: tcworld GmbH (ed) tekomJahrestagung 2012 in Wiesbaden: Zusammenfassungen der Referate. tekom Jahrestagung, Wiesbaden, p 460

31. Uschold M, Gruninger M (1996) Ontologies: principles, methods and applications. Knowl Eng Rev 11(2):93-136. doi:10.1017/S0269888900007797

32. Deutsches Institut für Normung (2000) DIN 2344:2000-05 Ausarbeitung und Gestaltung von terminologischen Festlegungen in Normen. Beuth, Berlin

33. Deutscher Terminologie Tag e.V (2014) Terminologiearbeit Best Practices 2.0. Dt. Terminologie-Tag, Köln

34. iglos - the intelligent glossary [www.iglos.de/app]

35. Suonuuti H (1998) Terminologia gvidilo. Universala Esperanto-Asocio, Rotterdam

\section{Submit your manuscript to a SpringerOpen ${ }^{\odot}$ journal and benefit from:}

- Convenient online submission

Rigorous peer review

- Immediate publication on acceptance

- Open access: articles freely available online

- High visibility within the field

- Retaining the copyright to your article

Submit your next manuscript at $>$ springeropen.com 